\title{
MÁXIME E INCLUSIVE: DOS ADVERBIOS LATINOS EN ESPAÑOL
}

\author{
Carmela Pérez-Salazar Resano \\ Universidad de Navarra \\ Grupo de Investigación Siglo de Oro (GRISO) \\ cpsalazar@unav.es
}

\begin{abstract}
Resumen
Este artículo desarrolla un estudio diacrónico de los adverbios latinos máxime e inclusive en español. Además de situar cronológica y textualmente sus primeras apariciones en nuestro idioma y de comprobar su propagación, se presentan en estas páginas las sucesivas manifestaciones de sus valores y se describe la transición de unos a otros; en definitiva, se examina comparativamente, y en relación con otros elementos, su comportamiento en español.

El análisis histórico muestra que máxime e inclusive no solo comparten la condición de adverbios latinos. Incorporados discretamente al castellano en el siglo $\mathrm{XV}$, han trascendido diafásica y diastráticamente: del uso formal al informal, y, aunque en distinta proporción para uno y otro, de los hablantes más cultos a usuarios de diverso nivel sociocultural.
\end{abstract}

PALABRAS CLAVE: Español, diacronía, latinismos, adverbios.

\begin{abstract}
This article develops a diachronic analysis of the Latin adverbs máxime and inclusive in Spanish. This study situates their first chronological and textual appearances in our language and proves their spread; and, at the same time, the successive manifestations of their value and the transitions between their consecutive functions are described. Lastly, their behavior in Spanish is examined from a comparative perspective that takes into account as well other elements of language.

The historical analysis shows that máxime and inclusive share not only their status as Latin adverbs but also their linguistic evolution. After a discreet incorporation into the 15th century Castilian, these adverbs transcended diaphasic and diastratically: from formal to informal language, and ?though in different degree for each one? from the most cultured speakers to users of varied socio-cultural level.

KEYWORDS: Spanish, diachrony, latinisms, adverbs.
\end{abstract}

\section{Introducción}

En este trabajo me propongo prestar atención a la presencia histórica en nuestro idioma de dos adverbios latinos ${ }^{1}$, máxime e inclusive. Mi interés por

1 Remito, para una revisión de las diversas interpretaciones de los conceptos cultismo y latinismo, a De Bustos Tovar (1974: 20-24 y 28-33); Clavería Nadal (1991: 2-36 y 43-69); y García Gallarín (2007: 25-29). 
estos elementos nace de la observación de que comparten características de diverso orden dignas de atención, y que reclaman su consideración conjunta; además de la categoría adverbial y de su condición de latinismos, coinciden en su empleo como signos capaces de señalar la mayor relevancia del miembro discursivo al que afectan².

Pero hay un rasgo que invita, en particular, al análisis diacrónico: máxime e inclusive son formas latinas que, incorporadas y asentadas en el español culto y formal, y por tanto de empleo restringido, han trascendido al uso popular e informal, en su caso sin abandonar el ámbito social y el registro desde el que se introdujeron. Quiere esto decir que, a partir de un tiempo que está por averiguar, es posible observarlas en moldes textuales, en situaciones y en usuarios diversos. En cuanto a las razones de su propagación social, tal vez la condición de latinismos -elementos extraños, por tanto, para buena parte de los hablantes- sea la que ha ejercido de reclamo entre ciertos usuarios del idioma, que sienten la necesidad de imitar formas de expresión que consideran modélicas ${ }^{3}$.

Así pues, parece oportuno analizar cómo se manifiestan los valores que describen gramáticos y lexicógrafos en distintos períodos de la historia del español, y, en particular, perseguir a través de un corpus la extensión cuantitativa y cualitativa de estos adverbios ${ }^{4}$. Una visión de su recorrido en nuestro idioma puede permitir averiguar en qué momento los hablantes han seleccionado cada una de estas formas y en qué contexto -social o textual- y situación -formal o informal- han quedado establecidas; esto es, cómo se distribuyen diastrática y diafásicamente ${ }^{5}$.

2 Resumo aquí las consideraciones de algunos autores respecto de estos elementos en español actual: Kovacci (1999: 775-76) anota el valor focalizador del adverbio máxime. Santos Río (2003: s.v. máxime e inclusive) describe inclusive como adverbio híbrido entre lo modal y lo aditivo, y señala también su valor ponderativo. Máxime es, para este autor, adverbio subjúntico focalizador de resalte. Martín Zorraquino y Portolés (1999: 4097-98) consideran que inclusive es un conector aditivo capaz de indicar que el segundo miembro discursivo es el que posee mayor fuerza argumentativa. Si bien no parece ser este el valor más atendido en el caso de inclusive, lo anotan Santos Río (2003: s.v.) -que añade además el dato de que muchos expertos no lo consideran- y Martín Zorraquino y Portolés (1999: 4097).

3 Para García Gallarín (2007: 36), "La innovación mediante cultismos se da en los estratos más influyentes [...] La vulgarización de usos cultos obedece al prestigio de los introductores de cultismos". Benítez (1956: 247-248) se refiere también a esa propagación. 4 Los datos que he obtenido para este trabajo proceden del Corpus Diacrónico del Español (CORDE) y del Corpus de Referencia del Español Actual (CREA) de la Real Academia Española. Reproduzco los testimonios sin alteraciones. Después del fragmento anoto, entre paréntesis y por este orden, fecha, autor, obra -en su caso, documento o artículo y publicación a la que pertenece- y país de procedencia. Presento los testimonios numerados para facilitar el comentario.

5 Respecto de la distribución diatópica, anoto la procedencia de todos los testimonios reproducidos, y señalo aquellos casos en los que existe un empleo característico o exclu- 


\section{Máxime: otro latinismo en castellano bajomedieval}

El adverbio latino máxime que, en español actual, actúa como focalizador de resalte o intensificador ${ }^{6}$, se incorpora a nuestro idioma en el siglo XV, y su presencia es discreta, según revelan las bases de datos académicas, hasta el siglo XX.

Para partir de una visión global de la presencia histórica de máxime, reproduzco, por centurias, el número de testimonios que ofrecen las bases de datos consultadas ${ }^{7}$ :

\begin{tabular}{|c|c|c|c|c|c|c|c|}
\hline SIGLO & XV & XVI & XVII & XVIII & XIX & $\begin{array}{c}\text { XX } \\
\text { (hasta } \\
1975)\end{array}$ & $\begin{array}{c}\text { XX (desde } \\
\text { 1975) -XXI }\end{array}$ \\
\hline TESTIMONIOS & 26 & 56 & 10 & 14 & 129 & 161 & 642 \\
\hline
\end{tabular}

\subsection{El siglo XV. Un latinismo para la focalización}

No puede extrañar, tratándose de un latinismo, que los primeros testimonios del uso de máxime se descubran en una etapa del desarrollo del español en la que, como es sabido, se registra una nutrida entrada de voces cultas procedentes del latín (además, es forma adverbial muy frecuente en textos en latín de la misma época) ${ }^{8}$. Su valor consiste, como, entre otros usos, en la lengua de la que se adopta, en señalar la relevancia del miembro discursivo que encabeza9.

Las primeras documentaciones de máxime en nuestro idioma constituyen casos aislados. El primero de ellos, de 1460, aparece en un Tratado de música anónimo:

sivo. Ahora bien, sin descartar el interés del factor geográfico, que podré tener en cuenta en trabajos posteriores, mi intención en estas páginas es atender, de manera prioritaria, a los factores diastrático y diafásico.

6 Así lo describen Kovacci (1999: 775-76), que incluye este adverbio entre los focalizadores particularizadores; Moliner (DUE: s.v. máxime y "expresiones intensivas", s.v. intenso); y Santos Río (2003: s.v.).

7 Respeto la organización de las bases de datos académicas y anoto separadamente el siglo XX hasta 1975 (datos del CORDE), y los años comprendidos entre 1976 y 2004 (datos del CREA).

8 Lapesa (1983: 110) señala: "A partir del Renacimiento, latinismos y grecismos dieron vestido a las nuevas ideas y sirvieron como elemento estilístico de primordial importancia." A la introducción de cultismos en el castellano de los siglos XIV-XV se refieren, entre otros, De Bustos Tovar (1974: 51-52); Harris-Northal (1999); Verdonk (2004: 902908); y García Gallarín (2007: 391-399).

9 Sobre la focalización y los adverbios focalizadores, véanse Kovacci (1999: 772-778); König (1991) y Cifuentes Honrubia (2002). 
(1) Estas reglas se guardan maxime en el contrapunto llano por que en lo diminuido segund los modernos cantan no se guardan todas vezes (1460, Anónimo, Tratado de música).

Poco tiempo después, Hernando del Pulgar ofrece otro (obsérvese que máxime afecta a un segmento superior a un sintagma ${ }^{10}$ ):

(2) Señor: muy acepto dezís que os parezco a mi señor el cardenal. Grande vista deue ser, por cierto, la vuestra, pues tan lexos vedes lo que yo no veo tan cerca. Si a la comunicación llamáis acepción, alguna tengo, como los otros, pero do no ay merced no creáys que ay acepción por grande que sea la comunicación, máxime que sabréis, señor, que ni me comunica mucho su señoría ni me da nada su magnificencia (1470-1485, Hernando del Pulgar, Letras).

Hay que esperar a 1499 para encontrar, en el Vocabulario eclesiástico de Rodrigo Fernández de Santaella, 24 de los 26 casos que ofrece el CORDE. Un empleo tan recurrente se explica no ya por la necesidad del castellano de adoptar una forma precisa (otros elementos eran capaces de expresar el mismo valor), sino más bien por una decisión consciente de utilizar el término latino, y sobre todo por las características particulares del texto, cuyo contenido se ocupa de señalar el significado y los valores gramaticales, en castellano, de formas latinas. Así pues, máxime aparece trasladado del latín al español en una obra lexicográfica en la que conviven las dos lenguas, y lo hace con uno de los valores que posee en latín, esto es, destaca este adverbio la mayor relevancia del componente del enunciado que le sigue, sea este parte de sintagma, sintagma o estructura más compleja (valga señalar que, en los testimonios que ahora interesan, ese componente es habitualmente un complemento del predicado, sea cual sea su estructura):

(3) Arthemo.onis. pe. pro. masculino genero et hoc arthemum. mi. vela chica. Maxime en agua dulce (1499, Rodrigo Fernández de Santaella, Vocabulario eclesiástico. España).

(4) Bestia. Tie. Femenino genero bestia que es animal sin razon. maxime quando es fiera (Ibídem).

(5) Pinnaculum, li. Neutro genero la cima, dizese de pinna que significa la altura de cada cosa. E maxime delos templos o muros (Ibídem).

De este valor se desprende su uso como recurso para acotar el significado de una palabra, ya que es capaz de restringir un significado ya descrito ${ }^{11}$ :

10 A la combinación máxime que, que aparece en este testimonio, me referiré más adelante.

11 Kovacci (1999: 776) explica que los particularizadores señalan "el predominio del elemento en foco", pero no excluyen "miembros del universo o conjunto involucrado". 
(6) Nidor.doris. masculino género de nideo.es. [...] Significa olor maxime de cosa assada (Ibídem).

En resumen, a juzgar por los testimonios examinados, el adverbio latino maxime se introduce en las manifestaciones escritas de nuestro idioma, como tantos otros latinismos, en un período de notable enriquecimiento léxico del español a través del latín, y su discreta entrada se ve favorecida por un entorno latino, sea este contextual o debido a los conocimientos del autor.

Como he señalado, y siempre según datos del CORDE, el empleo de este adverbio es escaso en el siglo XV; es de notar que no lo registra Nebrija en su Vocabulario español-latino, y tampoco, más de un siglo después, Covarrubias en su Tesoro de la lengua castellana o española ${ }^{12}$.

Por otro lado, su incorporación al grupo de signos focalizadores no supone una reestructuración: máxime no provoca la pérdida de otro u otros elementos de idéntico valor en un paradigma ya nutrido ${ }^{13}$. Así pues, el grupo se enriquece con un nuevo miembro, que en principio va a estar condicionado diastrática y diafásicamente (este adverbio parece encontrar su lugar en la prosa científica y didáctica). Una vez introducido en nuestro idioma, interesa comprobar cómo sucede su difusión.

\subsection{El siglo XVI}

El siglo XVI revela un aumento discreto del uso de este adverbio, pero se observa una concentración similar a la señalada para la centuria anterior. Tal vez lo más relevante del uso de máxime en este tiempo es el hecho de que, de los 56 testimonios hallados ${ }^{14}, 17$ se encuentran en La lozana andaluza, de Francisco Delicado (1528), que se ha caracterizado como modelo de obra que busca plasmar el habla con la utilización de elementos y construcciones

12 En el Tesoro hay un testimonio de este adverbio, pero se encuentra en un fragmento de una carta del Padre Sebastián Sarmiento, incluida en la voz casulla: que probasen con toda reverencia posible ellos solos y el que tenía la llave de la cámara santa abrir aquella arca para saber el tesoro que escondía, máxime la casulla de la Sanctísima Virgen (Covarrubias, Tesoro: s.v.).

13 Según he podido comprobar en el CORDE, a modo de muestra y sin afán de exhaustividad, sobre todo conoce este valor ya desde el siglo XIII (si bien es minoritario frente a su empleo como sintagma o formante de sintagma con función de aditamento o suplemento): deuen se dexar de todas las lauores $\&$ otrossi de mercar $\&$ sobre todo de fazer pecado (1256-1263, Alfonso X, Primera Partida). Especialment(e) es siempre focalizador, y se encuentra desde el castellano del siglo XIII, como la locución en especial (testimonios de ambos en CORDE).

14 Como he señalado para el siglo XV, también en el XVI abundan los textos escritos en latín, o fragmentos de textos en latín, visibles en el CORDE, en los que se utiliza este adverbio, y que no tengo en cuenta. Lo mismo sucede en los siglos XVII y XVIII. 
característicos del medio oral (Oesterreicher, 2004: 755) ${ }^{15}$. Así pues, junto a su continuidad en traducciones del latín y en textos históricos y didácticos ${ }^{16}$, aparecen testimonios en pasajes literarios dialogados.

Aunque no sea posible determinar con certeza que máxime se empleara efectivamente en el intercambio oral, así habla Aldonza:

(7) Pues ¿adobado no hacía? Sobre que cuantos traperos había en la cal de la Heria querían proballo, y máxime cuando era un buen pecho de carnero (1528, Francisco Delicado, La lozana andaluza. España).

(8) Yo, señora, vengo de Levante y traigo secretos maravillosos que, máxime en Grecia, se usan muncho (Ibídem).

Y así Marzoco:

(9) Vení, que es contento, porque más merecéis, máxime si le socorréis (Ibídem).

En cuanto al valor que transmite, es el mismo hasta aquí señalado: este adverbio particulariza la relevancia del elemento que le sigue respecto de otros no excluidos, explícitos o no ${ }^{17}$, y ese elemento focalizado ocupa un hueco sintagmático completo o el de constituyente de sintagma:

(10) Que todos se vistan de sus ropas de la tierra, por cuanto la desnudez es contraria a la doctrina cristiana, y amiga de toda suciedad y bellaquería: máxime los señores (1526, Marcos de Aguilar, Carta del licenciado Marcos de Aguilar, y documentos anexos. México).

(11) Dando claramente a conocer a todos los que la conversaban, y máxime a su marido, que aquella mujer era llena de divinidad (1528, Juan Justiniano, Instucción de la mujer cristiana, de J.L. Vives. España).

15 Frago (1988: 58-59) apunta, entre otras características, la presencia de elementos del lenguaje coloquial, especialmente en las partes de más intenso diálogo. Sin embargo, incluye máxime entre la nómina de cultismos que se encuentran en esta obra. Y es que Delicado, señala este autor, "utiliza los recursos propios del español de su tiempo, aunque pasados por el tamiz de la formación intelectual recibida" (Ibídem: 64).

16 Así, en la traducción de Juan Justiniano Instrucción de la mujer cristiana, de J.L. Vives, se encuentran 13 testimonios. Lo emplean también Gonzalo Fernández de Oviedo y fray Bartolomé de Las Casas, tanto en sus escritos en latín como cuando escriben en español (véase CORDE). Según parece, y como afirma Dworkin (2004: 651), «La introducción de algunos latinismos se debe a una decisión consciente de algún escritor culto [...] que buscaba la palabra adecuada y precisa para expresar cierto concepto".

17 Hay un testimonio de 1550 excepcional, en el que máxime actúa como aditivo en combinación con como, y señala, por tanto, la idéntica relevancia de los dos miembros: pues que no hay cosa que mas cierta sea en acabarse que la vida, y maxime á los que imos por la posta como los que andamos en este arte (1550, Bernardo de Aldana, Copia de carta original escrita del maestre de campo... España). 
(12) Cuanto a las demás que se hallan en tierra firme, máxime las que no son de vuelo muy ligero, es mejor camino decir que fueron por do los animales de tierra que allá hay de los de Europa (1590, José de Acosta, Historia natural y moral de las Indias. España).

(13) Sed ciertas que, si la Lozana pudiese festejar lo pasado, o decir sin miedo lo presente, que no se ausentaría de vosotras ni de Roma, máxime que es patria común, que voltando las letras, dice Roma, amor (1528, Francisco Delicado, La lozana andaluza. España).

Ocasionalmente, se combina con la conjunción copulativa y ( $e$ en testimonios anteriores, como el reproducido en 5). Entiendo, en estos casos, que el valor aditivo de la conjunción se desvanece, y que la combinación y máxime dirige la atención, si se quiere con más intensidad, hacia lo destacado como más relevante:

(14) Señora, somos todos vuestros servidores, y máxime si nos dais remedio a un acidente que tenemos (1528, Francisco Delicado, La lozana andaluza. España).

(15) Comoquiera que el Espíritu Santo que en ella moraba, resplandecía en sus ojos y en su cara [...], dando claramente a conocer a todos los que la conversaban, y máxime a su marido, que aquella mujer era llena de divinidad (1528, Juan Justiniano, Instrucción de la mujer cristiana de J.L. Vives. España).

\subsection{Siglos XVII-XVIII}

Si el empleo de máxime durante el tiempo hasta aquí descrito se muestra escaso, aún lo es más en las centurias siguientes. No varían, de cualquier modo, ni el valor ni los moldes textuales a los que parece estar vinculado: prosa científica, histórica y didáctica, y ahora también jurídica (obsérvese el entorno latino, antes comentado, ahora en el testimonio 18):

(16) Me ha parescido que, quanto más fáciles son en la forma, que más fácilmente son entendidas, máxime semejantes máquinas que suben agua por espulsión o por atracción (1605, Anónimo, Los veintiún libros de los ingenios y máquinas de Juanelo Turriano. España).

(17) El cual envió a excusarse con muy grande afecto [...] diciendo que más estaba para ir a dar cuenta a Nuestro Señor, que para admitir y tomar a su cargo cosas temporales: máxime donde tan principales caballeros había para ejercer aquel oficio (1612, Ruy Díaz de Guzmán, Historia argentina del descubrimiento, población y conquista de las provincias del Río de la Plata. Paraguay).

(18) Optime enim uero -le interrumpió luego el dómine-, ésa es la primera obligación de los padres, maxime cuando Dios les ha dado bastantes 
conveniencias (1758, José Francisco de Isla, Historia del famoso predicador Fray Gerundio de Campazas alias Zotes. España).

Respecto de la concentración de testimonios, la mitad de los casos hallados en el siglo XVII pertenece a una misma obra ${ }^{18}$ (Los veintiún libros de los ingenios y máquinas de Juanelo Turriano), mientras que en el XVIII se puede observar un uso más disperso. En cualquier caso, durante tres centurias, el corpus utilizado no permite hablar de una presencia generalizada de este elemento en español, sino más bien esporádica y condicionada por factores textuales, y, especialmente, por la formación y por el gusto individual de algunos autores ${ }^{19}$, lo cual sitúa los casos hallados en La lozana andaluza más en el autor que en los personajes que crea.

\subsection{Siglos XIX-XX. Extensión y combinaciones}

El siglo XIX representa no sólo un incremento notable en el empleo de máxime, en frecuencia absoluta (el número de casos hallados sobrepasa ya la centena) y en cuanto al número de autores que se sirven de él ${ }^{20}$, sino otras novedades respecto de centurias anteriores: si hasta entonces el corpus manejado ofrecía un uso mayoritario en textos escritos en latín y excepcional en textos en español, ahora la proporción se ha invertido, no porque disminuya su empleo en aquellos, sino porque crece considerablemente el número de testimonios en español (129 casos, frente a 88 en latín).

Como cabía esperar, máxime continúa apuntando, de manera no excluyente, a la mayor relevancia del elemento que le sigue, que, con frecuencia, expresa una circunstancia -a menudo temporal- o condición (obsérvense los testimonios tomados de los textos de leyes, en los que habitualmente focaliza una cláusula introducida por si) respecto de la información presentada anteriormente o que se va a presentar de inmediato: puede suceder, si bien no es la organización más frecuente, que el miembro destacado por este adverbio -recuérdese su carácter circunstancial o incidental, que le otorga libertad

18 Valga observar una curiosidad acerca de esta concentración en el siglo XVIII. Feijóo emplea con asiduidad este adverbio cuando escribe en latín, y, aunque menos, también lo hace Luzán. Ninguno de los dos, sin embargo, lo emplea, según datos del CORDE, en español. 19 García Gallarín (2007: 216-217) habla de cultismos de autor y cultismos generacionales, máxime, en los primeros siglos en que se documenta, podría considerarse cultismo de autor. 20 Aun así, se debe señalar que algunos autores lo emplean de forma recurrente; así, Concepción Arenal, José María Pereda o Antonio Pirala, en castellano, y Marcelino Menéndez Pelayo, en latín. También los anónimos textos de leyes son generosos en el uso de este adverbio. Esto mismo sucede en el siglo XX. 
de colocación- se anticipe a la información principal ${ }^{21}$. En definitiva, máxime aparece vinculado, aunque no restringido, a ciertos segmentos oracionales, y precisamente de esa vinculación van a surgir las combinaciones máxime cuando, máxime si y máxime que 22 .

En cuanto a los moldes textuales en que se presenta, el corpus examinado manifiesta la continuidad de máxime en la prosa culta, sobre todo en la de contenido histórico y en la didáctica, en los textos legales y ahora también en la narrativa. Este siglo proporciona, además, los primeros testimonios procedentes de la prensa:

(19) La relación de los que existían en aquel tiempo voy a expresarla: por ella podrá inferirse los que posteriormente se hayan promovido, máxime cuando no hubo para ello reales resoluciones (1837, Pedro De Angelis, Apuntes históricos sobre la demarcación de límites de la Banda Oriental y el Brasil. Uruguay).

(20) Aunque el fanatismo religioso (...) no se igualase nunca en la Helvecia al que dominó largo tiempo en nuestra infortunada España (...), todavía era potente entre ciertas clases de la sociedad, y todavía -máxime siendo activado por influencias tan eficaces como la del señor de Montsalvens- podía levantarse amenazador e irresistible (1857, Gertrudis Gómez de Avellaneda, La velada del helecho o el donativo del diablo. Cuba).

(21) Sin que á la apertura del cadáver se pueda ver lesión alguna de la mucosa que nos indique las alteraciones que ha sufrido esta, como sucede en las inflamaciones, máxime cuando esta ocasiona ulceración, induraciones $\mathrm{u}$ otra modificación (1876, Ecequiel Martín de Pedro, Manual de Patología y clínica médicas. España).

(22) El rico, máxime si la riqueza es heredada, es muy raro que la emplee en otra cosa que en satisfacer sus gustos y vanidades (1880, Concepción Arenal, La cuestión social. España).

(23) Transcrita en el poder la cláusula testamentaria por la que el marido nombró heredera á su mujer, no carece ésta de personalidad en tales conceptos, máxime si se aportaron los documentos oportunos en el período de prueba (1881, Ley de Enjuiciamiento Civil. España).

21 Anoto aquí un caso excepcional, perteneciente a esta centuria, en el que máxime aparece ponderado en una expresión comparativa que puede tener intención humorística: $L a$ mala calidad de este artículo no deja de constituir una de las faltas y privaciones que esperimenta el español, máxime si acaba de dejar las finas aguas de Madrid, y aún más máxime todavía si el español fuese abstemio ó aguado (1842, Modesto Lafuente, Viajes de fray Gerundio por Francia, Bélgica, Holanda y orillas del Rhin. España).

22 Es muy escasa la presencia de la secuencia y máxime, que, como anotaba, no tiene valor de conector aditivo. 
(24) Un aura socialista palpitó en sus palabras que estremecieron la fábrica toda, máxime cuando el desconcierto de la Hacienda dio lugar a que se retrasase nuevamente la paga en aquella dependencia del Estado (1883, Emilia Pardo Bazán, La Tribuna. España).

(25) Que á la humanidad entera debe interesar que la pesca no disminuya, máxime á aquellas clases que más o menos directamente viven de ella, es una verdad que está en la conciencia de todos (1885, Cándido Ríos, Agentes perjudiciales a la pesca. Revista de pesca marítima. España).

(26) Nos parece inoportuna la resolución de la Comisión de Gobernación, y es de esperar que el Ayuntamiento no la apruebe, máxime tratándose de una corta cantidad (1899, Anónimo, El Noticiero Universal. Diario independiente de noticias, avisos y anuncios. España).

Respecto de su presencia en obras literarias, máxime aparece de nuevo en secuencias que reproducen realizaciones orales (como el diálogo entre $\mathrm{D}^{\mathrm{a}}$ Irene y D. Diego de El sí de las niñas, o el de D. Ramiro y D. Robustiano de Tipos y paisajes, o la intervención del Señor Candelas en La revoltosa ${ }^{23}$, aquí incluidos). Naturalmente, no es posible determinar si se trata de una forma elegida conscientemente para reflejar lo que podía ser ya habitual en el intercambio coloquial del momento o si el adverbio forma parte del caudal de recursos de un autor culto.

(27) Doña Irene: ¿Qué quiere usted? Criada sin artificio ni embelecos de mundo, contenta con verse otra vez al lado de su madre [...] no es maravilla que cuanto hace y dice sea una gracia, y máxime a los ojos de usted, que tanto se ha empeñado en favorecerla (1805, Leandro Fernández de Moratín, El sí de las niñas. España).

(28) Y si ese villano tiene un hijo y solicita para éste su hija de usted al mismo tiempo que ofrece el préstamo, acceder a sus pretensiones, máxime siendo el hijo honrado (1871, José María de Pereda, Tipos y paisajes. España).

(29) Señor Candelas. -¡Vamos, quita! / Un momento de alborozo / no es ninguna cosa ilícita, / pero un funcionario público / de cierta categoría, / máxime cuando es hombre / de costumbres fidedignas, / goza, pero se contiene / en cuanto recapacita (1897, José López Silva, La Revoltosa. España).

Sin embargo, en este tiempo hay noticias explícitas sobre la extensión diafásica de este adverbio. En definitiva, si los testimonios del corpus no permiten, por sí solos, extraer conclusiones, apreciaciones como esta manifiestan que máxime había traspasado la frontera del uso formal: el Diccionario usual de la Real Academia Española, que incluye este término desde su edición de

23 Véase Seco (1970: 155-167) sobre el cultismo en el habla popular. 
$1803^{24}$, señala explícitamente el ámbito familiar en el que se utiliza -y añade que es "voz puramente latina"-25. Esta información desaparece, no obstante, de los diccionarios académicos desde 1914, y no vuelven a encontrarse referencias semejantes en otras obras lexicográficas consultadas ${ }^{26}$.

Por último, los datos del corpus correspondientes al siglo XX (hasta 1975) revelan la continuación de las tendencias señaladas: la presencia de máxime en español aumenta paulatinamente ${ }^{27}$, aunque esta presencia no deja de ser discreta si se compara, por ejemplo, con la de inclusive, al que me referiré a continuación. La prosa histórica y didáctica, y también los artículos periodísticos de contenidos diversos ${ }^{28}$, son los géneros donde este adverbio se manifiesta mayoritariamente, especializado, como hasta este momento, en anunciar el predominio del segmento que introduce. Además, ha producido combinaciones de uso recurrente: máxime si, máxime cuando, máxime que. Es capaz, sin embargo, de aparecer en otros contextos ${ }^{29}$.

(30) Es falta subsanable la omisión en el mandamiento de la clase de los terrenos colindantes, máxime si se hacen constar el tomo y libro en que la finca está inscrita (1909, Anónimo, Ley Hipotecaria. España).

(31) Que se me diga qué valor tiene el espíritu de caridad -máxime si éste se encuentra en una sociedad egoísta y por ende poco cristiana- (1926, Miguel Ángel Asturias, ¿ Nueva orientación de la Universidad Popular? [París 1924-1933. Periodismo y creación literaria]. Guatemala).

(32) Ciertamente, no es posible seguir a Lukács por este camino sin compartir la deformación oportunista del pensamiento de Hegel a que conduce su obra, máxime cuando aquí se trata de dar una explicación de las relaciones entre filosofía y sociedad (1950-1968, Jesús Fueyo Álvarez, Estudios de teoría política. España).

24 A través del NTLLE, s.v., he podido comprobar que hay un diccionario bilingüe que lo incorpora casi un siglo antes: es el New Spanish and English Dictonary de Stevens, publicado en 1706, en el que máximamente y máxime se equiparan al inglés chiefly.

25 Salvá lo anota también (Nuevo diccionario: s.v.) como propio de la conversación familiar (véase NTLLE, s.v. máxime).

26 En 1970, al significado 'principalmente' que se presentaba en exclusiva desde la edición de 1803 del Diccionario usual, se añade 'en primer lugar'. En el Diccionario manual de 1984 y de 1989 se define, en cambio, así: 'con más motivo o más razón'; y, a partir de 1992, el Diccionario usual ofrece estos significados: 'En primer lugar', 'principalmente', 'sobre todo'. Cfr. NTLLE: s.v. máxime para esta información, y también para su presencia en diccionarios no académicos, que lo incorporan desde 1846.

27 El CORDE ofrece, en este siglo, 161 ocurrencias de este adverbio en español, y 50 en pasajes y obras escritos en latín.

28 Cfr. Pérez-Salazar (2010).

29 Además de estas combinaciones, máxime + cláusula en gerundio es una estructura de uso frecuente. 
(33) En estos momentos se anunció que el corredor español Carmelo Morales había abandonado el "Tour", posiblemente resentido tras el formidable esfuerzo que le había supuesto la escalada del Aubisque, máxime teniendo en cuenta su deficiente estado físico a consecuencia de la caída que sufrió hace dos días (1958, Mencheta, Bahamontes, vencedor en la cima del Aubisque ... [ABC, 9 de julio de 1958]. España).

(34) A pesar de todo, de su actitud dependerán los términos del pacto que, tarde o temprano, habrán de suscribir los de arriba y los de abajo; máxime con la Restauración en ciernes (1971, Max Aub, La gallina ciega. Diario español. España).

Considero oportuno dedicar unas líneas a la combinación máxime que, documentada, según se ha visto, desde los primeros testimonios, aunque de presencia más discreta que otras, y que comienza a encontrarse con regularidad en el siglo XX. Al contrario que para máxime cuando o máxime si, menos polisémicas, no es fácil determinar el valor semántico, e incluso la relación sintáctica, que establece que en la combinación máxime que, que introduce, como las anteriores, secuencias de estructura oracional.

La lectura de los testimonios hace posible interpretar que aporta causalidad, de manera que la fórmula completa parece señalar como relevante la causa ('especialmente porque'), causa que se refiere al enunciado expresado con anterioridad; así pues, tendría un valor semejante al que presenta L. Santos Río (2003: s.v.) para máxime cuando, que describe como "de orientación causal explicativa" 30 . Sin embargo, interpreto que, en algunos casos (como en 35 y 37), es también posible una lectura con valor de conector aditivo enfático ${ }^{31}$. Obsérvese que la secuencia podría ser sustituida, en los testimonios arriba reproducidos, por más aún, y especialmente o equivalente, lo cual no sucede en otros contextos. En definitiva, considero que, en algunos casos, máxime que puede ser considerada ambigua semántica y sintácticamente.

(35) Porque la impunidad es difícil y la pena grave, máxime que el amenazador $[. .$.$] se cuida poco de pensar que el castigo se ha de medir por la$ amenaza (1865, Concepción Arenal. Cartas a los delincuentes. España).

(36) Es frecuente verse obligado a establecer la diferenciación con una neoplasia estenosante o una estrictura orgánica de origen inflamatorio, máxi-

30 Se refiere este autor a su presencia en contextos evaluativos de conveniencia, obligación y deber.

31 No mencionan este valor Kovacci (1999); Santos Río (2003: s.v.); Moliner (DUE: s.v. máxime e intenso, que, sin embargo, equipara máxime a las locuciones es más y más aún); M. Seco et alii (DEA: S.v.), y tampoco los diccionarios académicos (NTLLE: s.v. y DRAE: S.v.). Acín (1998: 167) señala que los marcadores es más, más aún y máxime "presentan valores próximos a la adición". 
me cuando a estos procesos puede sumarse el espasmo (1964, M. Díaz Rubio, Lecciones de patología y clínica médica. Aparato digestivo. España).

(37) La presencia de tales fenómenos trombóticos tiene importancia y más dada su asociación a la eosinofilia tisular, la dilatación linfática y los infiltrados perivasculares, máxime que [...] es frecuente que junto a ellos existan formaciones granulomatosas (Ibídem).

(38) -Venga, Luque Calvo, tú solito, dentro -dijo Plinio empujándole sobre el brocal-. Vosotros sujetar la maroma... ¡Que a mí no me moja nadie, Juan sin Tierra, máxime que hoy estrené el uniforme! (1968, Francisco García Pavón, El reinado de Witiza. España).

Por otra parte, es digno de mención el hecho de que la presencia de máxime en lo literario, en el siglo XX, revela un empleo más generoso, y que se encuentra en pasajes que buscan reproducir el uso coloquial (en los testimonios 38 y 39 se puede hablar, además, de oralidad):

(39) - ¡Qué mala nota, mana Hilaria! No sea cándida. Un retoño de la nobleza más esclarecida y acaudalada de estos lados a ninguna soltera le perjudica. Cualquier mozo se da tres caídas por ella, máxime si es tan linda y tan sazonada como esta muchachita suya (1928, Tomás Carrasquilla, La marquesa de Yolombó. Colombia).

(40) La dije que parara la jaca, que yo era yo, y poco hombre había de ser si la permitía trabajar, máxime en sus circunstancias (1958, Miguel Delibes, Diario de un emigrante. España).

(41) María del Coro expresó, por gruñido, lo inconveniente de tal tema en presencia de un jefe, aunque pequeño, máxime siendo ella secretaria de gran jefe (1972, Juan García Hortelano, El gran momento de Mary Tribune. España).

Ahora bien, es a partir de 1975 cuando las tendencias hasta aquí descritas se observan con la rotundidad que garantiza la abundancia de datos: si bien no varían ni su valor ni los moldes textuales, a partir de esta fecha se hace más evidente el doble camino que ha tomado máxime, como también el grado de permanencia en cada una de estas vías.

Por un lado, mantiene su empleo mayoritario en el uso culto y formal que le vio incorporarse, y así se encuentra en textos especializados que versan sobre diversas materias (política, medicina, música, gastronomía, deportes, hasta 179 casos), y ahora esencialmente en la prensa escrita, también especializada, donde manifiesta más de la mitad del total de casos. Continúa, en menor grado, en las creaciones literarias. Los testimonios periodísticos que recogen intervenciones orales son escasos, y se observa, para estos últimos, una presencia más numerosa en publicaciones procedentes de países latinoa- 
mericanos. El corpus ofrece ya testimonios de empleo en otras realizaciones orales, pero la mayor parte de estas suceden en situaciones de formalidad ${ }^{32}$.

Por otro lado, y en cuanto a la extensión diafásica, el número de testimonios lleva a pensar en un empleo no muy recurrente en producciones informales, pero sí bien documentado: máxime se presenta en diálogos y entrevistas recogidas en la prensa, y también en diálogos literarios que reproducen situaciones de informalidad.

Por último, la extensión social de este adverbio se manifiesta en algún testimonio procedente de la prensa (así en 56), y también en usos contrarios a la norma, muy escasos en el caso de máxime ${ }^{33}$. Ofrezco, en las líneas que siguen, una selección de testimonios -organizados según el medio y la formalidad- tomados del CREA:

Testimonios escritos formales. Prensa escrita, prosa especializada y obras literarias

(42) Mi opinión es que la delincuencia -máxime la que brota de las chabolas o casas-colmenas- es siempre fruto de una determinada estructura social (1977, Triunfo. España).

(43) Ni tampoco aquellas reivindicaciones (...) poseen la suficiente entidad como para justificar tales tipos de acciones incontroladas como las que se pretenden; máxime, cuando se convoca en términos tan vagos y ambiguos como se ha hecho (1977, El País. España).

(44) Es improbable que puedan reconocer a los que siguen ahí abajo, máxime cambiando continuamente de vagones y de trenes (1980, Julio Cortázar, Queremos tanto a Glenda y otros relatos. Argentina).

(45) Estos aspectos quedan fuera del alcance de este libro y deben ser tratados en un curso de Petrología más avanzado, máxime cuando en muchos casos no puede conocerse la composición exacta de un mineral (1989, Antonio Castro Dorado, Petrografía básica. Texturas, clasificación y nomenclatura de rocas. España).

(46) Honduras se envolverá en la vergüenza internacional si acepta que los militares violadores de los derechos humanos no sean castigados, máxi-

32 Un testimonio del año 2003 tomado del CREA, de Miguel Ángel Ruiz Orbegoso, Sugerencias para aprender a exponer en público, en el que se explica el valor de este elemento, revela que se considera recomendable servirse de él en las intervenciones orales formales.

33 El hecho de que el DPD no incluya una referencia respecto del uso normativo -sí lo hace para inclusive- revela que el empleo de este adverbio no supone un problema para los usuarios de la lengua, seguramente porque, a diferencia de inclusive, máxime abandona más discretamente el estrato social al que ha estado restringido desde sus primeras manifestaciones (cfr. Pérez-Salazar 2009). 
me cuando se asista a Europa a pedir asistencia económica (1997, La Tribuna. Honduras).

(47) Y es así que se advierte que, al leer que Bernal dice que, en una jornada se trasladaron de Cempoala a Jalapa, al punto le enmienda la plana, diciendo que eso es imposible, máxime en tiempo de aguas (2001, Juan Miralles, Hernán Cortés. Inventor de México. México).

\section{Testimonios orales-formales}

(48) Otro tema sobre el que debemos repetirnos es el relativo al gigantesco endeudamiento de nuestro gobierno nacional, máxime cuando la inversión pública es prácticamente irrelevante (1998, Senado de la Nación, Sesión especial. Argentina).

(49) Desde ese punto de vista me inclino más hacia la globalización, hacia la correlación de todas las áreas, máxime si se permite que hay temas comunes objetivos comunes (Sin fecha. Conferencia. Venezuela).

Testimonios orales-coloquiales. Intervenciones orales recogidas en prensa o tomadas de medios orales. Testimonios literarios

(50) -Todos, todos lo creíamos, tienes razón, Eulalia, máxime que el médico le aseguró que había sido una falsa antina (1976, Rosa Chacel, Barrio de las Maravillas. España).

(51) OLGA. -Yo no adulo a nadie. No, no. Soy amable. Quiero serlo. Eso es lo que me enseñaron desde que era chiquita así. Y máxime en un día como hoy (1985, David Viñas, Maniobras. Argentina).

(52) En cambio no creo que sepan distinguir muy bien, en medio de un borlote, cuáles son los alborotadores malos y cuáles los buenos, máxime si éstos andan por ahí rompiendo cristales (1987, Antonio Velasco Piña, Regina. México).

(53) Sí, bueno, tanto como planificarlo tan exactamente como tú dices no, pero sí que es cierto que a lo largo de un año, máxime cuando hay [...] varias competiciones simultáneas como son las competiciones españolas [...] es imposible mantener un tono siempre (1989. Domingo Deporte. España).

(54) "[...] no fue un exceso de confianza, porque en un partido, máxime de copa, no debe haber ese aspecto pues relajarse con pelotas difíciles de jugar es humano..." (1996, Excélsior. México).

(55) "Es duro cuando el dinero no llega a tiempo, máxime si hay familia de por medio, uno tiene que andar de un equipo a otro y hoy día es difícil encontrar una institución que sea estable", comentó Sergio Guillén (1997, Prensa Libre. Guatemala). 


\section{Testimonio de extensión diafásica}

(56) Páramo fue localizado sobre las cinco de al tarde, mientras comía en un bar de la localidad de Cerceda y fue obligado a regresar a la granja. "Le dijimos que no iba a pasar nada, máxime cuando la Guardia Civil ya estaba allí", afirman los trabajadores (1987, Trabajadores de Mafriesa retienen a un accionista... El País. España).

\section{Uso no normativo}

(57) Con las teclas -/+ (23), en el renglón STOP ponga el tiempo que queda pro (sic) televisar, 4 horas como máxime en pasos de 15 minutos (1998, Instrucciones impresas 1998. España).

\section{Inclusive. Del latín medieval al romance}

A diferencia de máxime, el adverbio inclusive se formó en el latín escolástico ${ }^{34}$. Incorporado al romance en el siglo XIV, ha recorrido un camino similar al de aquel, como señalaba al comienzo de estas páginas, si bien difieren en cuanto a frecuencia, valores y textos en los que se encuentran históricamente, y en especial en cuanto al grado de difusión y a las noticias que se tienen acerca de su extensión social.

Los gramáticos y lexicógrafos actuales anotan siempre, o destacan en primer lugar que, situado detrás de la secuencia a la que afecta, inclusive señala que esta ha de ser incorporada en una serie expuesta antes (DUE, DEA y DRAE 2001). Otras veces precisan que ha adquirido, con posterioridad en el tiempo, la capacidad de expresar adición enfática que posee incluso ${ }^{35}$; y algunos mencionan también su empleo como focalizador no aditivo (Martín Zorraquino y Portolés, 1999: 4097 y nota 44). La compleja variedad de valores y matices que manifiesta este latinismo, y que se descubre en la diacronía, se puede reducir a esta acertada propuesta de Santos Río (2003: s.v.), que lo presenta como un híbrido "entre lo modal y lo aditivo". Por otro lado, son abundantes las indicaciones explícitas, a lo largo del tiempo, respecto de la

34 DRAE 2001: s.v. No hay testimonios de este adverbio en textos latinos medievales incluidos en el CORDE. Véase Pons Rodríguez (2010), para un estudio pormenorizado y contrastado sobre el origen, propagación, valores y comportamiento gramatical de los adverbios bajolatinos inclusive, exclusive y respective.

35 La Academia, en el DPD: S.v., presenta este uso como posterior y señala que es ya tradicional y está autorizado por escritores de prestigio. Martín Zorraquino y Portolés (1999: 4097) consideran también los dos valores; describen inclusive como "conector aditivo" que indica que el miembro discursivo al que afecta debe ser tenido en cuenta o es más relevante que otro $u$ otros en una escala argumentativa. 
extensión diastrática de inclusive, así que no sólo es posible verificarla a través de testimonios directos, sino también por la referencia, en obras especializadas, a una alteración morfosintáctica recurrente ${ }^{36}$.

En cualquier caso, estimo que la descripción del desarrollo histórico de inclusive no debe separarse de la de dos parientes muy próximos, incluso e inclusivamente, con los que comparte, históricamente, valores y contextos ${ }^{37}$. Por el momento, dejo constancia del número de casos por centurias que ofrece cada uno de ellos ${ }^{38}$, y que permite comprobar su desigual difusión:

\begin{tabular}{|c|c|c|c|c|}
\hline SIGLO & TESTIMONIOS & \multicolumn{3}{|c|}{} \\
\hline & inclusive & incluso & inclusivament(e) & inclusiv(e)ment(e) \\
\hline XIV & 4 & 1 & 1 & 1 \\
\hline XV & 53 & 23 & 0 & 1 \\
\hline XVI & 93 & 57 & 5 & 2 \\
\hline XVII & 68 & 87 & 4 & 0 \\
\hline XVIII & 106 & 6416 & 0 & 0 \\
\hline XIX & 286 & & 1 & 2 \\
\hline XX \\
$\begin{array}{c}\text { hasta } \\
\text { 1975) }\end{array}$ & 514 & 47.164 & 0 & \\
\hline $\begin{array}{c}\text { XX (desde } \\
1975) \text {-XXI }\end{array}$ & 3.217 & & & \\
\hline
\end{tabular}

\subsection{Siglos XIV y XV. El paradigma de la 'inclusión'}

Las primeras manifestaciones de este adverbio en un romance peninsular son, como he podido constatar, anteriores a las de máxime (y a las del participio incluso). Los testimonios más antiguos que recoge el CORDE se encuentran en documentos aragoneses, en concreto en un escrito notarial y en un ordenamiento legal de finales del siglo $\mathrm{XIV}^{39}$. Si en el primero inclusive se pos-

36 Me refiero a la formación del plural inclusives (DPD, s.v. inclusive. Como señalaba antes, el DPD no incluye referencias a un posible uso incorrecto de máxime).

37 No he tenido en cuenta la forma incluido (y variantes flexivas), ya que, a diferencia de incluso, nunca abandona su condición de participio. Lo mencionaré ocasionalmente al tratar sobre incluso.

38 Incluyo, en el cómputo total de las primeras centurias, los testimonios que proceden de textos aragoneses, si bien en la descripción menciono la procedencia geográfica.

39 Lleal (1995: 21) advierte de la irradiación de los modelos culturales aragoneses (en Aragón la renovación literaria y cultural se produce en la segunda mitad del siglo XIV) hacia Castilla. Harris-Northal (1999: 1) se refiere a la introducción de latinismos en el español tardomedieval a través de Aragón, y relaciona este hecho con el contacto inmediato de Aragón con Italia. También Pons Rodríguez (2010: 85), señala que Aragón se adelanta en la introducción de latinismos que luego se encuentran en castellano. 
pone al miembro que expresa una cantidad que ha de entenderse como límite que se incluye (obsérvese que, a la indicación del límite, y como corresponde al estilo reiterativo de los escritos notariales, se añade otra expresión, "et no más avant", para que no exista duda respecto del límite de esa cantidad), en 2 y 3 se encuentra antepuesto a las secuencias a las que afecta. En estos últimos, en los que interesa igualmente asegurar la correcta comprensión, la indicación de inclusividad no afecta a una cantidad sino a una tipología, y parece anticiparse a la interpretación del receptor.

(1) El dito çalmedin sia tenido encontinent crear qui conozca de cualesquiera feytos civiles puyantes entro a summa de cinquanta sueldos jaqueses inclusive et no mas avant (1391, Anónimo, Ordinación dada a la ciudad de Zaragoza por el rey don Juan I).

(2) El procurador de la Ciudat pueda fazer part legitima et acusar los ditos criminosos de los sobre ditos crimenes et delictos et dar su demanda criminal et proseguir aquella entro a difinitiva sentencia inclusiue condepnatoria o absolutoria (1396, Anómino, Ordinaciones ciudad Barbastro).

(3) Et acusar los ditos criminosos de los sobreditos crimens et delitos et de qualquier de aquellos et dar su demanda ceuil o criminal et proseguir aquellas entro a diffinitiua sentencia inclusiue Condempnatoria (1396, Ordinaciones ciudad Barbastro).

De igual procedencia y del mismo tiempo (los testimonios se encuentran, asimismo, en un texto notarial) son las primeras formaciones en -mente, inclusiu ment e inclusivament, pospuestas al elemento que expresa el término de un plazo, término que ha de incluirse ${ }^{40}$ :

(4) Et prometo, conviengo e me obligo de ir personalment a la dita ciudat de Calatayut por fazer e obrar el dito retaulo daquia por todo el mes de Febrero primero venient inclusivament (1396, Anónimo, Renovación de un contrato de Guillén de Leví para pintar un retablo...).

(5) Daquia el dia e fiesta de Todos Santos la ora primera venient inclusiu ment (Ibídem).

En las mismas fechas se sitúa la primera aparición en romance del participio incluso, cuyo valor parece ambiguo en el único testimonio que ofrece este siglo: se puede interpretar como participio (coordinado a circundado) o como

40 Obsérvese que el adverbio se construye no solo sobre la base adjetiva en femenino -como es normal en las formaciones adverbiales en -mente- sino también sobre la base adverbial inclusive (en el testimonio, apocopada). Para esta formación y para el plural inclusives, remito a Pérez-Salazar (2009). 
conector aditivo enfático; en cualquier caso, es el aragonés Juan Fernández de Heredia ${ }^{41}$ quien se sirve de él:

(6) La qual cosa obtenida et impetrada del senado, como la batalla fuesse començada et el padre subitament huuiesse visto a su fillo el consul combatiendo estar circundado et incluso en medio de los enemigos por Poncio (1376-1396, Juan Fernández de Heredia, Traducción de la Historia contra paganos, de Orosio).

Por otro lado, antes señalaba, respecto de máxime, que su incorporación no supone una reestructuración paradigmática; pues bien, en este caso es posible afirmar que con la entrada en nuestro idioma de inclusive, incluso e inclusivamente se inaugura un paradigma de formas especializadas en señalar la inclusión ${ }^{42}$ que van a desarrollar diversos valores y matices a lo largo del tiempo, como es mi intención mostrar.

En el siglo XV, inclusive continúa presente en los textos procedentes de Aragón y aparece en los de Castilla. Además del incremento numérico, es posible observar la continuidad en cuanto al tipo textual respecto de los primeros testimonios: este adverbio se emplea mayoritariamente en ordenamientos legales y textos notariales, pero, aunque en menor medida, aparece también en otros escritos en prosa culta. Su misión consiste en señalar la inclusión de una cantidad, un tiempo, un lugar físico o un concepto cualquiera que se presentan como límite. En esa referencia comparte contexto con $a$, hasta o equivalente (cfr. entro a, en el testimonio 7), o con de o desde si se refiere al límite inicial. Obsérvese, además, que, unido a la conjunción copulativa e, ejerce ya como conector aditivo (testimonio 8), si bien su empleo con este valor es todavía excepcional:

(7) E lo que del tiempo de la dita publicacion entro a la difinitiua sentencia inclusiue deuido le sera en el tiempo de la dita sentencia o un mes apres judicialment demande o interpelle seyer le pagado (1414, Anónimo, Ordinación dada a la ciudad de Zaragoza por el rey don Fernando I (el de Antequera)).

(8) E de la parte de la dicha villa de Salvatierra de Alava fasta los montes e terminos de Hubarrundia e de Ayllarte, e inclusive todos los dichos

41 García Gallarín (2007: 376-78) considera que Fernández de Heredia es una figura decisiva por su contribución al enriquecimiento del castellano; es, señala, uno de los introductores y divulgadores de cultismos.

42 El participio incluido (y variantes flexivas) se encuentra por vez primera en el siglo XIV. Su propagación numérica en los siglos posteriores es más discreta que la de incluso, pero, además, esta variante no ha desarrollado otros valores. En cualquier caso, incluso e incluido comparten contextos durante siglos, hasta que aquella se especializa definitivamente como partícula de foco. 
montes e terminos que entre medias cahen ayan los dichos lugares e vezindades communeros (1430, Anómino, Concordia [Documentación del Archivo municipal de Salvatierra]).

(9) En asi que, durante el presente nuestro guiaje, el qual queremos que dure por tiempo de seis meses, del dia de la data de las presentes en adelante contaderos inclusive, e no mas (1494, Anómino, Fernando otorga seguro [Documentos sobre relaciones internacionales de los Reyes Católicos]. España).

(10) E otrosí por la presente, del caso mayor al menor inclusive, de nuestro proprio motu (...) vos perdonamos la pena de este mundo (1500, Anónimo, Privilegio de don Juan II. España).

Fuera de este género, hay un autor, Enrique de Villena, y una obra, Traducción y glosas de la Eneida, que ofrece un tercio de los testimonios hallados. En definitiva, la presencia de inclusive parece condicionada por dos factores: el gusto individual (como en el caso de máxime) y la procedencia geográfica del autor (cfr. infra sobre incluso en Villena).

Pues bien, si en Villena inclusive señala, como en los documentos notariales, el extremo de una cantidad o concepto que se ha de incorporar (es llamativo, por cierto, su empleo constante para referencias textuales -ver testimonio 12-), esto es, tiene una función esencialmente informativa, en otros casos adquiere un valor añadido: esto sucede cuando la referencia explícita, no ya a la inclusión, sino al propio límite, es innecesaria; entonces la transmisión precisa de la información cede su lugar a la relevancia expresiva. Es lo que sucede en el testimonio 13, en el que, además, ese extremo al que se dirige la atención ni siquiera se presenta como posible, sino que tiene un sentido hiperbólico:

(11) E por eso le quedó el nombre qu'el rey Ilión le puso cuando primero lo hedificó; que ovo desd'él fasta Priamo inclusive tres reyes (1427-1428, Enrique de Villena, Traducción y glosas de la Eneida. Libros I-III. España).

(12) La primera, desde su principio fasta aquella palabra de lexos inclusive, son palabras exçitativas e consultivas, al padre dirigidas; la segunda comiença desde vosotros fasta donde dize tancto peligro inclusive (Ibídem).

(13) E si otras cosas vuestra dominaçion a mí mandar querrá cumpla, pensar puede non dubdaré de lo seguir, la pública honestad servada, fasta la esfusión de la propria sangre inclusive (Ibídem).

Respecto de otros miembros del paradigma, en un texto aragonés se encuentra la formación inclusivament, única en esta centuria, que también se refiere al límite que ha de incluirse: 
(14) Et attendida solament la verdat del fecho en todos los actos de aquell entro a diffinitiua sentencia inclusiuament (1414, Anónimo, Ordinación dada a la ciudad de Zaragoza por el rey don Fernando I (el de Antequera)).

El participio incluso, incorporado al castellano, como decía antes, en el siglo XIV, ofrece en el XV escasos testimonios ${ }^{43}$. Es cierto que predomina su empleo con valor participial, pero este siglo nos lo ofrece ya como conector aditivo $^{44}$ y en su papel de focalizador (organizo los testimonios de acuerdo con el orden de valores aquí enumerado):

(15) Otorgar la dicha bulla de indulgencia para la dicha confradria e confradres della, que son o por tiempos seran, iuxta forma del memorial, que en esta sera incluso (1497, Anónimo, Don Fernando al obispo de Cartagena... España).

(16) Porque les fué dado por bendición, incluso notado por seso natural (1450, Anónimo, Carta de propuesta de arbitrio [Los cuadernos de alcabalas]).

(17) A los que hacía tiempo se les vedaba incluso el paso (1485-1488, Anónimo, Documentación medieval abulense en el Registro General del Sello).

Quiero destacar, no obstante, algunos testimonios de este mismo siglo cuya interpretación considero dudosa: no es fácil decidir si incluso actúa como participio o si es adverbio de foco. En esta ambigüedad reside, a mi entender, el interés de estos casos, ya que permiten apreciar el tránsito de uno a otro valor: del hecho de quedar incluido se accede, en contextos en los que incluso se refiere a lo que se presenta como extremo de una escala ${ }^{45}$, a la relevancia de esa inclusión ${ }^{46}$. Valga indicar que la posición de incluso no es determinante para una u otra interpretación, pero la anteposición a un sustantivo facilita la lectura como partícula de foco:

43 No considero las variantes flexivas de incluso porque no me interesa documentar aquí el uso de este participio, aunque sí tenerlo en cuenta en el masculino singular (del que procede, inmovilizado, el uso como adverbio de foco), para constatar y contrastar numéricamente los valores que manifiesta a lo largo del tiempo.

44 Parece sencillo el tránsito, desde el significado del participio incluso, como desde inclusive, a su empleo como conector aditivo (que manifiesta también desde sus primeras apariciones en el CORDE, habitualmente unido a la conjunción copulativa): el miembro que sigue a este participio queda incorporado en el mismo periodo o secuencia que el que precede.

45 Sobre incluso y hasta en escalas culminativas, véase Portolés (2007: 145-46). En pág. 144 recuerda el significado de la preposición hasta: "indicar el límite de una trayectoria espacial, temporal, de actividad o de cantidad". Desde este valor puede también acceder a su empleo como focalizador, cuando se enfatiza ese límite señalado por hasta. Para el origen de los valores de hasta, véase Martínez (1992).

46 Como se puede apreciar en los testimonios 18 a 20, también Enrique de Villena ejerce como propagador de incluso. De los 23 testimonios hallados en este siglo, 7 pertenecen a este autor. 
(18) Entrava la mar aun entr'ellos e çercava las cavernosidades, siquiere oquedades, de aquellos montes, respondientes al valle de enmedio; e el viento incluso, non podiendo salir, multiplicávase (1427-1428, Enrique de Villena, Traducción y glosas de la Eneida).

(19) Más dize a Eolo, que reine en la cueva çerrada de sus vientos, casi diziendo que se esté incluso en la posibilidat e potençia del franco alvedrío (1427-1428, Enrique de Villena, Traducción y glosas de la Eneida).

(20) Non solamente las ondas eran tancto elevadas e depremidas, mas aun quebrantadas e agitadas de incluso viento sin fortuna (1427-1428, Enrique de Villena, Traducción y glosas de la Eneida).

\subsection{El siglo XVI}

El adverbio inclusive, documentado más tempranamente que máxime, experimenta también una difusión más rápida ${ }^{47}$. Hay que anotar que, en esta centuria, el lugar habitual de inclusive lo constituyen, como hasta este momento, los textos notariales y ordenamientos legales, en los que son constantes las referencias a límites precisos. En menor proporción aparece en tratados y en obras científicas ${ }^{48}$.

Inclusive se sitúa tras el término que expresa el límite que se ha de incluir (en ocasiones ese límite señala el punto de partida), sea este espacial, temporal, cuantitativo, conceptual o textual (obsérvese que algunos autores lo colocan entre pausas). Así pues, es constante su presencia en contextos del tipo hasta $X$ inclusive; desde $X$ inclusive):

(21) No haya vacaciones si no fuere desde la vispera de Navidad inclusive, hasta el segundo dia despues de los Reyes (1530, Fuero reducido de Navarra. España).

47 En el siglo XVI el CORDE ofrece 93 casos, bien es cierto que concentrados en 29 documentos. Respecto de su presencia en en textos latinos incluidos en el CORDE, frente a lo señalado para máxime, inclusive se presenta en algún pasaje de fray Bartolomé de las Casas escrito en latín y en dos referencias a escritos en esta lengua. Se utiliza también en una secuencia en la que se parodia la pedantería: Aquí lo verás inclusive (...) y si no, cátale aquí intensivo, que extensivo no puede ser, y en fin, le has de ver virtualiter (1593, Lucas Gracián Dantisco, Galateo español).

48 Pese a las diferencias, máxime e inclusive coinciden en algunos aspectos: a la concentración de testimonios hay que añadir que la presencia de este último se ve también favorecida, como cabía esperar, por un entorno latino. Así sucede, por ejemplo, en los Estatutos hechos por la muy insigne Universidad de Salamanca, de 1594 -que representa un tercio del total de las apariciones de inclusive en el siglo XV- en los que son frecuentes expresiones, incluso párrafos enteros, en latín. Sucede esto mismo en los testimonios de fray Bartolomé de las Casas (cfr. nota 15 sobre el uso de máxime en este autor) al que pertenecen 16 de los 93 casos hallados en el CORDE. Las Casas se sirve de este adverbio cuando escribe en castellano y en latín. 
(22) De suerte que, desde el Dean, hasta el Acólito inclusive, el que no asistere á alguna hora en el coro, carezca del estipendio (1538, Anónimo, Erección de la Iglesia de Cuzco [Documentos relacionados con el Sínodo e Santiago de Chile]. Chile).

(23) Y así torno a redecir que todas las conquistas y guerras que desde que se descubrieron las Indias, hasta hoy inclusive, se han hecho contra los indios, fueron siempre y han sido injustísimas (1552, fray Bartolomé de las Casas, Controversia entre las Casas y Sepúlveda. España).

(24) Y desde el dicho año hasta el de ochenta y cinco, inclusive, parece por los libros reales haberse quitado treinta y cinco millones (1590, José de Acosta, Historia natural y moral de las Indias. España).

(25) De la primera parte se lea el primer año desde la cuestión primera hasta la veintiséis inclusive (1594, Anónimo, Estatutos hechos por la muy insigne Universidad de Salamanca. España).

(26) Porque ya desde él inclusive en adelante, vienen a ser yguales las cuerdas poligonias a los dos lados que sustentan (1598, Juan Alfonso de Molina Caro, Descubrimientos geométricos. España).

Sigue siendo excepcional su empleo como conector aditivo (siempre junto a la conjunción copulativa):

(27) Por la parte del Oriente tiene de frontera e costa esta gobernación, desde el puerto de la Herradura, cient leguas, e inclusive el golfo de Nicaragua al sud de Orotiña (1535-1557, Gonzalo Fernández de Oviedo, Historia general y natural de las Indias. España).

Aunque minoritaria (puesto que este adverbio parece haber quedado vinculado a textos que buscan transmitir la exactitud, y en los que, por tanto, toda información resulta indispensable), continúa su presencia en contextos expresivos, en los que no interesa determinar con precisión un margen, sino señalar enfáticamente el extremo de un alcance:

(28) Pero, supuestas las guerras e injurias, daños, agravios e injusticias, muertes y robos que se les han hecho -que nunca naciones del mundo de otras tales las rescibieron-, no deben un maravedí, antes tienen derecho de hacer justísima guerra contra todo español hasta el día del jucio inclusive (1527-1561, Fray Bartolomé de las Casas, Historia de las Indias. España).

(29) Y en esta fe y creencia protesto e afirmo que quiero vivir lo que me resta de la vida y hasta el fin della, que es la muerte inclusive (1566, Anónimo, Cláusula del testamento que hizo el obispo de Chiapa... España).

Otros integrantes del paradigma de la inclusividad antes citados manifiestan una presencia más discreta en este siglo: incluso continúa en su papel de 
participio (30), que todavía predomina, pero crece su uso como conector aditivo enfático (31) y como adverbio de foco (32):

(30) Declaran que la dicha villa tiene por termino propio todo lo que esta incluso en la moxonera (1575-1580, Anónimo, Relaciones topográficas de los pueblos de España. Madrid. España).

(31) En este pasaje se demuestra suficientemente que el obispo por derecho divino está obligado, y bajo la amenaza de la condenación eterna si no lo hace, a insistir con todas las fuerzas, e incluso a anhelar importunamente la liberación del rebaño, su defensa, la preservación de todos los peligros y males corporales y temporales ((1552, Fray Bartolomé de las Casas, Tratado sobre los indios que han sido hechos esclavos [Tratados de 1552]. España).

(32) Ahora bien, entre esos actos, no sólo figuran los de regir y enseñar a la plebe encomendada, y proveerla en lo espiritual, sino también el defenderla y preservarla de todos los peligros, aflicciones y agresiones, incluso corporales (1552, Fray Bartolomé de las Casas, Tratado sobre los indios que han sido hechos esclavos [Tratados de 1552]. España).

Aún es posible encontrar casos de dudosa interpretación, como los que mencionaba antes, en los que no parece posible determinar si se manifiesta la inclusión de un término o si ese término se señala, además, como el más relevante:

(33) Escribió con él el Marqués á Ambrosio de Aguiar, como la parte de la armada de S.M. con que venía se hallaba muy pujante y con 5500 soldados embarcados en ella, incluso el tercio de D. Lope de Figueroa con 1800 de los de Flandes (1582, Anónimo, Lo subcedido á la armada de S.M. de que es capitán el Marqués de Santa Cruz... España).

En cuanto a las formaciones adverbiales en -mente, inclusivamente aparece escasamente: el CORDE registra cinco casos en esta centuria. Este adverbio (al igual que la forma inclusivemente, antes mencionada) comparte con inclusive el valor de indicador de inclusión de un límite ${ }^{49}$.

(34) Porque si así fuese, no hay que dudar, sino que desde entonces inclusivamente sería injusto, tiránico e inicuo el tal señorío (1552, Fray Bartolomé de las Casas, Controversia entre Las Casas y Sepúlveda [Tratados de 1552]. España).

(35) En tal caso el dicho Martín de Tapia no tenga obligacion de pagar al dicho Hieronimo de Mora los dichos treinta y quatro escudos sino seis meses despues del dicho dia de todos sanctos inclusivemente... (1569,

49 La misma manifestación excepcional se observa en los siglos posteriores: en el XVII hay 2 testimonios; en el XVIII, 4 testimonios; ninguno en el siglo XIX; uno en el XX, hasta 1975. A partir de esta fecha, esto es, en el CREA, no aparece ningún caso, pero sí de inclusivemente. 
Anónimo, Jerónimo de Mora, ensamblador, hace un contrato con el pintor Martín de Tapia para entregarle... España).

\subsection{Siglos XVII-XVIII}

Los siglos XVII y XVIII permiten hablar de continuidad y renovación en el uso de inclusive: por un lado, se aprecia una presencia constante de este adverbio latino en nuestro idioma. Se mantiene en los tipos textuales que lo vieron aparecer -es característico de ordenamientos legales ${ }^{50}$ y documentos notariales- y transmite los valores descritos hasta aquí. No obstante, aumentan los casos en que el adverbio se antepone al término que señala (de valor conceptual, no cuantivativo) y entonces se aproxima a la función de focalizador (testimonio 40) que ya manifiesta incluso:

Conviene destacar, al igual que para máxime, la concentración de testimonios en ciertos autores, así que interviene también, como factor determinante en el uso de este elemento, el estilo individual (Las Casas y Feijoo, entre otros, lo utilizan con regularidad).

(36) Los becerros están avaluados, desde el rio de Toa, por la parte del Norte, y desde el rio de Luisa, inclusive en contorno, hasta esta ciudad (1645, Anónimo, Sínodo de San Juan de Puerto Rico de 1645... Puerto Rico).

(37) Y desde este dia inclusive se à de dar buelta á la tabla hasta ajustar doscientos y sesenta dias en el mismo signo (1656, Fray Jacinto de la Serna, Tratado de las supersticiones, idolatrías, hechicerías, ritos y otras costumbres gentílicas... México)

(38) Habrá Juntas semanarias en cada Provincia desde Noviembre hasta Junio inclusive (1774, Anónimo, Estatutos aprobados por S.M. para Gobierno de la Real Sociedad Bascongada de Amigos del País. España).

(39) Véase en el tomo séptimo, discurso 5, desde el núm. 28, hasta el 39 inclusive, una dilatada, eficaz, ardiente invectiva contra los delirios hereticales (1739, Benito Jerónimo Feijoo, Theatro Crítico Universal. España).

(40) Y dijo que todas las tardes venían á rezar, entre grandes y chicos, como quinientos, inclusive las mujeres (1775, Juan Fernández de Bobadilla, Información sobre Talamanca [Documentos para la historia de Costa Rica]. Costa Rica).

Por otro lado, en el siglo XVII se inicia una tímida presencia de este latinismo en lo literario, y, si bien no varían los valores hasta aquí descritos, pre-

50 En el siglo XVII es generosa la presencia de inclusive en los documentos que recogen constituciones sinodales de distintos países americanos. Se emplea también en tratados científicos. 
cisamente en este ámbito se produce un precioso testimonio de la extensión social de inclusive: lo emplea el alcalde del Entremés de los Galeotes, de Quiñones de Benavente, para dictar una carta, en una secuencia en la que se expresa un plazo, pero en la que no cabe el uso de un indicador de límite. Además del efecto cómico, es interesante comprobar en este pasaje cómo la popularización del latinismo trae consigo la alteración de su valor:

(41) No quisiera ser largo; y assi digo, que me condeno a galeras por diez años inclusiue (1651, Luis Quiñones de Benavente, Entremés de los galeotes [Vergel de entremeses]. España).

Pero, además, esta misma centuria inaugura (es decir, mucho antes que para máxime) las noticias que los expertos aportan acerca del adverbio: S. de Covarrubias le dedica un comentario extenso y preciso en su Tesoro ${ }^{51}$ :

Encerrado y contenido en otra cosa, de in et claudo, claudis. Incluir, comprehender y encerrar una cosa dentro de otra. Usamos vulgarmente deste término, aunque es latino y lógico. Dar término a Fulano de aquí al domingo inclusive, para que parezca, etc., entiéndese que el domingo está comprehendido con los demás días, y que pareciendo en todo el domingo cumple con el mandato del superior; al contrario, si dijera exclusive.

Los Diccionarios académicos, desde Autoridades, le dedican sin excepción una entrada, y lo equiparan a inclusivamente como adverbio que expresa la inclusión en una cuenta o serie. Es general la indicación "adverbio latino", o, en algún caso, como en las ediciones del Diccionario usual entre 1837 y 1869, "puramente latino". Sin embargo, no dan noticia sobre otros valores o sobre la extensión social de este adverbio. Y no será hasta la edición del Diccionario manual de 1950 cuando se añada una entrada *inclusives: barbarismo por inclusive (Real Academia Española: NTLLE, s.v. inclusive).

Por último, al siglo XVIII pertenece la primera documentación (sólo hay dos en esta centuria) de la secuencia ambos inclusive, que evita la repetición de la partícula en cada extremo que se limita y que se va a constituir en combinación recurrente:

51 Tesoro: s.v. incluso. Casi un siglo después, en 1706, Stevens lo incluye en su diccionario bilingüe (A new Spanish and English Dictionary); y también le conceden espacio otros diccionarios desde este siglo XVIII. Entre todas las referencias, cabe destacar que, en 1853, existe ya indicación explícita de la alteración morfológica de este latinismo; es en el Diccionario de Domínguez (Diccionario Nacional o Gran Diccionario Clásico de la Lengua Española), donde se comenta la pluralización del adverbio; el autor lo explica así: "Algunos cometen el disparate de formar plural de este adverbio puramente latino, cuando son dos o más los objetos incluidos" (datos consultados a través del NTLLE, s.v.). Remito, para la forma inclusives, a Pérez-Salazar (2009: 449-453). 
(42) Declaramos igualmente que la vacación de Pascua de Navidad debe durar desde el dia de la Natividad del Señor hasta el primero de Enero, ambos inclusive (1772, Anónimo, Real Cédula de Carlos III [Documentos para la historia de la Universidad de Salamanca]. España).

El participio incluso, en el siglo XVII, se mantiene en la misma proporción descrita hasta aquí respecto de inclusive, y en los mismos valores que en los siglos anteriores. Utilizado en cualquier manifestación de la prosa culta (no se puede atribuir, por tanto, a un género textual), su empleo como participio sigue siendo el más abundante ${ }^{52}$, si bien no faltan testimonios en los que la interpretación transita entre ese valor participial y el de adverbio de foco (así en 44):

(43) Y el dicho tercio y quinto es la parte de casa que está inclusa en la casa del dicho mi hermano [...] y más aranzada y media de majuelo jaen en el majuelo de la Cueva que está incluso con el del dicho mi hermano (1609, Anónimo, Testamento de Doña Catalina de Salazar... España).

(44) Se convinieron en que se pagase al Indio 24 reales por la semana, incluso el Lunes (1648, Juan de Solórzano y Pereira, Política indiana. España).

En otros contextos, todavía minoritarios, es ya indudable su valor de focalizador (45) y de conector aditivo (46) $)^{53}$ :

(45) Los encantamientos pueden incluso hacer bajar la luna del cielo (1611, Sebastián de Covarrubias, Suplemento al Tesoro de la lengua española castellana. España).

(46) Es necesario, e incluso el asunto lo exige, que junto a la iglesia se construyan claustros (1611, Sebastián de Covarrubias, Suplemento al Tesoro de la lengua española castellana. España).

En el siglo XVIII incluso conoce un incremento numérico aún discreto. Sin embargo, lo que comenzaba a dibujarse va adquiriendo ahora mayor proporción: es llamativo el contraste entre el valor participial, que mantiene en los escritos más rígidos, y los valores que le conceden la literatura y el ensayo ${ }^{54}$ : así pues, es posible afirmar que incluso se transforma, o desarrolla sus posibilida-

52 Los Diccionarios académicos, hasta el siglo XX, hacen una mención explícita del empleo exclusivo de incluso como adjetivo. Hay que esperar a la edición de 1925 del Diccionario usual para encontrar una distinción entre el uso adjetivo, el uso adverbial (equiparado a inclusivamente), y el que se considera uso preposicional, para el que se identifica con hasta (cfr. NTLLE, s.v.).

53 Obsérvese que ambos valores no tienen por qué ir siempre parejos, como señalan Martín Zorraquino y Portolés (1999: 4097, nota 44). En el testimonio 45, incluso no es conector aditivo, pero sí focalizador. No es casual, por cierto, que los dos testimonios que he reproducido sean de Covarrubias, ya que es este autor el que lo utiliza en todos los valores aquí descritos. 54 Es en la prosa literaria y ensayística donde incluso actúa como focalizador y como conector aditivo. Así en Isla, Concolorcorvo, Cadalso, Luzán y Moratín, entre otros. 
des, esencialmente, en manos de algunas de las principales figuras literarias de esta centuria:

(47) Auiendo nombrado a otros (se dio por notificado Pedro Fernández) ninguno otro se dio por notificado sino el incluso en este paréntesis (1750, Anónimo, Memorial presentado por Juan de Morales [Documentos lingüísticos de Uruguay]. Uruguay).

(48) Que han de poder cargar en las dichas fragatas, cualquiera género de frutos de la tierra, incluso hierro, acero, clavazón y herraje por lastre (1707, Anónimo, El rey aprueba asiento hecho con el márqués de Montesacro... España).

(49) ¿Quién impide que cada uno cultive en su propia lengua todos los saberes liberales, e incluso a las más graves Musas? (1742, Ignacio de Luzán, Defensa de España y participación en la campaña contra Gregorio Mayans. España).

(50) A los restantes (incluso el tuerto), que a juicio de los examinadores eran incurables, los encerraron en las jaulas de los locos (1789, Leandro Fernández de Moratín, La derrota de los pedantes. España).

En definitiva, para el siglo XVIII ha culminado la concurrencia de inclusive e incluso, aunque cada uno de ellos conserve un empleo o valor característico y exclusivo. Esa concurrencia se ha cumplido en virtud de una aproximación sintáctico-semántica recíproca que se observa diacrónicamente: el participio incluso se adverbializa especializado en el papel de focalizador y en el de conector aditivo enfático; inclusive, desde siempre adverbio, desarrolla, al menos numéricamente, los valores que en sus primeras manifestaciones eran excepcionales.

\subsection{Siglos XIX-XX. Extensión diafásica y diastrática}

Desde el siglo XIX, inclusive conoce un incremento notable en cuanto a frecuencia, que se hace extraordinario a partir de 1975 (y que lo sitúa en un grado de difusión que nunca alcanza máxime); pero, sobre todo, experimenta una ampliación, o, mejor dicho, redistribución, de valores y contextos. No abandona el valor con el que se introdujo en nuestro idioma e inauguró paradigma, y por este motivo encuentra siempre un espacio en cualquier texto en el que se haya de determinar algún límite. Este es, sin duda, su lugar habitual. Además, a partir del siglo XIX, lo que fue una ocurrencia, la reunión de ambos e inclusive, se ha convertido en fórmula cada vez más frecuente ${ }^{55}$ :

55 En el siglo XIX, esta combinación ofrece 18 testimonios. En el XX, hasta 1975, 14 Desde 1975, 67 testimonios, más un caso de ambos inclusives. 
(51) Los dueños de los bultos presentados con sello acudirán mañana 7 del corriente de 9 á 2 á la casa nacional de moneda para hacer el reconocimiento de los numerados desde el 1800 al 1822 ambos inclusive (1822, Manuel Ortiz, Comisión de recibo de medios luises [El imparcial]. España).

(52) Se dividen vulgarmente los 50 libros en tres tomos (...); el segundo, llamado Infortiatum, los catorce siguientes hasta el treinta y ocho inclusive (1869, Ricardo Ovidio Limardo, Manual de legislación romana o resumen histórico. Venezuela).

(53) Quedó aprobado el programa de los festejos para los días del Corpus y San Bernabé próximos, los cuales tendrían lugar en los días 8 al 14, inclusive (1939, Anónimo, Hace 25 años [Nueva Rioja] España).

La historia más reciente habla sobre todo de una extensión hacia el valor focalizador (antepuesto o pospuesto a la secuencia que señala) y hacia la adición enfática (con o sin conjunción copulativa -en este último caso va entre pausas-). El valor focalizador coincide con el empleo, cada vez más extendido, de este adverbio en lo literario, pero no es, en absoluto, exclusivo de la creación literaria.

En definitiva, en los últimos dos siglos parecen desdibujarse progresivamente las fronteras con el participio incluso, mientras que inclusivamente casi ha desaparecido. Reproduzco, a continuación, testimonios de los valores de inclusive en estas dos centurias:

\section{Conector aditivo enfático}

(54) Linares (villa), tiene subdelegado e inclusive en su partido una pequeña aldea o villa titulada el Parral de la Reina Luisa (1805-1806, Anónimo, Descripción geográfica de un nuevo camino de la gran cordillera... Chile).

(55) Anunció el burrero con profética gravedad que pronto se quitaría todo el dinero metálico y no quedaría más que papel, hasta para las pesetas, y que echarían nuevas contribuciones, inclusive, por rascarse y por darse de quién a quién los buenos días (1897, Benito Pérez Galdós, Misericordia. España).

(56) No por esto hemos de creer que Kelsen desecha su vieja idea de la posibilidad de elección entre ambas hipótesis. Inclusive nuestro autor ha llegado a reconocer la posibilidad de una teoría de las Uniones de Estados (1962, José Puente Egido, La teoría pura del Derecho y la ciencia del Derecho internacional. España).

(57) La consideración de la convención como modo de aplicación de normas generales (...) es fácil y hasta normal; puede decirse, inclusive, que esta manera de pensar de la doctrina tradicional viene dada por la circunstancia de que la teoría del contrato... (1962, José Puente Egido, La teoría del derecho y la ciencia del Derecho internacional. España). 


\section{Focalizador}

(58) La única persona con quien ella se atrevía a hablar algo de lo que le pasaba por dentro era don Tomás Crespo, libre, decía él, de todas las preocupaciones, inclusive la de no tenerlas, que era de las más tontas (1884-1885, Clarín, La Regenta. España).

(59) Perdimos cuanto teníamos, el orgullo inclusive (1893, Benito Pérez Galdós, Torquemada en la Cruz. España).

(60) Se explicaba que el hombre se adaptase a todo, la esclavitud inclusive, y que echase de menos el grillo y las rejas (1903, Emilio Bobadilla, A fuego lento. Cuba).

(61) Obedeciendo órdenes del alcalde de este pueblo, la Guardia civil, detuvo al vecino del mismo, Blas Iglesias Encinas, por haberes (sic) insolentado con mencionada autoridad, llegando inclusive a insultarle (1933, Anómino, Por insultos al alcalde [Región, 13 de Enero de 1933]. España).

(62) La C.N.T. fue, pues, dignidad y ejemplaridad militante, fue arrojo inigualable en el combate, fue lealtad y generosidad con todos sus aliados, inclusive hacia algunos que no lo merecían (1963, Anónimo, Ayer [Asturias. Órgano de la Confederación regional del trabajo...]. España).

Pero los últimos dos siglos de su recorrido histórico -especialmente el último- dejan, en particular, muchos testimonios de la extensión diafásica de este latinismo (se emplea en pasajes que reproducen intervenciones orales en situaciones de informalidad) y diastrática (aparece en boca de hablantes, reales o ficticios, de cualquier condición $\left.{ }^{56}\right)$ :

(63) -Señoras y señores, dijo con una copa de agua en la mano, es tanto mi agradecimiento, es tal la emoción que me embarga, que... lo digo yo y no me arrepiento, yo, Bonifacio Reyes, pago todo el gasto... eso es, toda la comida y toda la bebida... botillería inclusive (1891, Clarín, Su único hijo. España).

(64) Pero Saturna, al llevarle la carta, le dijo: "La señorita es casada, y ese D. Lope, que usted cree papá, es su propio marido inclusive" (1892, Benito Pérez Galdós, Tristana. España).

(65) EL ALCALDE (...) Yo no ando con repulgos; soy muy francote (...) Verdad que también doy cuanto tengo... el corazón inclusive (1897, Benito Pérez Galdós, El abuelo (novela en cinco jornadas). España).

(66) - ¡Usted se acomoda inclusive a la desgracia de don Daniel y de Paulina! (1921, Gabriel Miró, Nuestro Padre San Daniel. Novela de capellanes y devotos. España).

56 Valga destacar que el CREA ofrece cerca de 700 testimonios de este latinismo en fuentes orales reales; el valor que más se manifiesta en ellos es, por cierto, el de focalizador. 
(67) -Claro que sí. Pues todavía no nos hemos sacado una foto en la que salgamos toda la panda, Samuel y Zacarías, inclusive, y los demás- dijo Fernando (1956, Rafael Sánchez Ferlosio, El Jarama. España).

(68) El mandria este todo lo sabe, inclusive lo que uno puede y no puede hacer. ¡No te amuela! (1958, Miguel Delibes, Diario de un emigrante. España).

(69) Y esto, cada vez más, lo vemos ¿no? en productos inclusive fuera de esta línea, pues (1991, Radio Madrid. España).

(70) Y le dijo que no, que eso ya lo cambiaron por completo, y que inclusive cambiaron todo el personal de ahí, y que ahora sí caen de sorpresa ( $\sin$ fecha, encuesta oral). Venezuela).

Si inclusive ha incrementado en los últimos tiempos su presencia entre los hispanohablantes, el caso de incluso es mucho más llamativo. A partir del siglo XIX, supera numéricamente al adverbio latino, y desde comienzos del siglo XX alcanza una difusión que lo sitúa muy por encima de este $e^{57}$. Esos datos llevan a destacar un hecho: el participio incluso, que en sus primeras manifestaciones coincide con el adverbio en la restricción diastrática y diafásica, ha trascendido al uso común; es, se podría decir, un cultismo integrado ${ }^{58}$. El adverbio inclusive ha alcanzado una extensión cuantitativa y cualitativa notable, pero no ha perdido la consideración de forma modélica, asociada a un grupo social restringido (máxime e inclusive conservan su apariencia de latinismos) ${ }^{59}$, de ahí que mantenga intacto, hasta la actualidad, su atractivo para algunos hispanohablantes ${ }^{60}$.

57 Cfr. Pérez-Salazar (2010, 178 ss.). En este trabajo se muestra que inclusive, como focalizador, es característico de los medios hispanoamericanos, especialmente de los de México y Argentina.

58 No es mi objetivo presentar aquí una descripción rigurosa de los valores actuales de incluso, que ha sido ya descrito pormenorizadamente; únicamente, para concluir su recorrido histórico, me permito señalar que para el siglo XIX casi ha desaparecido su empleo como participio; se emplea, en cambio, como conector aditivo intra y extraoracional; pero, esencialmente, se ha especializado en destacar la relevancia del elemento al que se antepone (raras veces se pospone), respecto de una totalidad explícita o implícita. Remito, para una descripción del comportamiento funcional y de los valores de incluso -y otros elementos con los que puede concurrir- en español actual, a Fuentes Rodríguez (1987), Herrero Blanco (1987), Garrido (1993), Cuartero Sánchez (2002) y Portolés (2007).

59 Ahora bien, desde el siglo XIX los diccionarios no informan de la condición de latinismos de máxime e inclusive. Para el caso de máxime, las últimas advertencias en este sentido se encuentran en el Diccionario de Gaspar y Roig (1855) y en el Diccionario usual de la Real Academia de 1869. Para inclusive, en el Diccionario de Salvá (1846) y en el de Domínguez (1853) (datos obtenidos a partir del NTLLE: s.v).

60 Más que a usuarios de estratos socioculturales bajos, me refiero a hablantes con alguna formación que usan premeditadamente un elemento de apariencia culta. El hecho de que el adverbio inclusive -más extendido que máxime- sufra históricamente alteraciones cuando trasciende a hablantes que lo conocen pero ignoran su condición adverbial o su valor, puede ser indicativo de que su propagación sucede efectivamente desde ese sector social. 


\section{Conclusiones}

Al comenzar estas páginas anunciaba el objetivo de acompañar a los adverbios máxime e inclusive en su recorrido por nuestro idioma. Para este cometido, ha sido imprescindible el auxilio de las observaciones de gramáticos y lexicógrafos de distintos tiempos: a falta de más datos que, procedentes de otros moldes textuales, permitan asegurar, y situar cronológicamente, la extensión de estas y otras formas lingüísticas (en particular en épocas remotas), las apreciaciones de los expertos resultan ineludibles.

Llegados a este punto, creo posible afirmar que máxime e inclusive no sólo coinciden en su condición de adverbios latinos incorporados, en las mismas fechas, a un idioma en proceso de desarrollo. Si bien difieren en cuanto a su procedencia remota (latín clásico vs. latín medieval) y son diversos los datos que hablan de su irrupción en castellano (inclusive se introduce desde el aragonés) y difusión, comparten el hecho de haber conquistado un espacio que supera al de los hablantes y los contextos que les vieron nacer. Hoy es indudable su frecuencia en el español culto oral y escrito, pero han trascendido al uso informal -en particular en el caso de inclusive-, y, aunque en distinta proporción para uno y otro caso, se sirven de ellos hablantes de distinto nivel sociocultural.

\section{Referencias bibliográficas}

Acín, E. (1998): "Los marcadores de función textual "intensificación" es más, más aún y máxime". En Martín Zorraquino, M. A. y E. Montolío Durán (eds.): Los marcadores del discurso. Teoría y análisis. Madrid, Arco/Libros, págs. 163-176.

Benítez Claros, R. (1956): "La integración del cultismo", Archivum. Revista de la Facultad de Filología, VI, págs. 235-249.

Bosque, I. y V. Demonte (dirs.) (1999): Gramática descriptiva de la lengua española. Madrid, Espasa.

Bustos Tovar, J. J. de (1974): Contribución al estudio del cultismo léxico medieval. BRAE, Anejo 28. Madrid, Real Academia Española.

Cano. R. (coord.) (2004): Historia de la Lengua Española. Barcelona, Ariel.

Cifuentes Honrubia, J. L. (2002): "Sobre sintagmas sustractivos: preposiciones, focalizadores y marcadores discursivos", Estudios de Lingüistica de la Universidad de Alicante, XVI, págs. 5-59.

Clavería Nadal, G. (1991): El latinismo en español. Barcelona, Universitat Autónoma de Barcelona.

Covarrubias, S. de (Tesoro): Tesoro de la lengua castellana o española. Edición integral e ilustrada de I. Arellano y R. Zafra, Pamplona, Madrid y Frankfurt am Main, Universidad de Navarra e Iberoamericana-Vervuert-RAE, 2006. 
Cuartero Sánchez, J. M. (2002): Conectores y conexión aditiva: los signos incluso, también y además en español actual. Madrid, Gredos.

Domínguez, R. J. (1853) Diccionario Nacional o Gran Diccionario Clásico de la Lengua Española (1846-47). Madrid-París, Establecimiento de Mellado, 5a edición. 2 vols. (consultado a través de NTLLE, [DVD], Madrid, Espasa, 2001).

Dworkin, S. N. (2004): "La transición léxica en el español bajomedieval", en R. Cano (coord.), págs. 643-656.

Fuentes Rodríguez, C. (1987): "Pragmática y relación intratextual: el caso de hasta, incluso y ni siquiera”, Estudios de Lingüística de la Universidad de Alicante, IV, págs. 159-176.

Frago Gracia, J. A. (1988): "Norma lingüística y artificio literario en La lozana andaluza", Philologia Hispalensis, III, págs. 41-66.

García Gallarín, C. (2007): El cultismo en la historia de la lengua española. Madrid, Ediciones Parthenon.

Garrido, J. (1993): "Operadores epistémicos y conectores contextuales". En Diálogos Hispánicos. Aproximaciones pragmalingüísticas al español, H. Haverkate et alii (eds.), XII, Amsterdam, Editions Rodopi, págs. 5-50.

Gaspar y Roig, Biblioteca Ilustrada de Gaspar y Roig: Diccionario enciclopédico de la lengua española, con todas las vozes, frases, refranes y locuciones usadas en España y las Américas Españolas [...] Tomo I. Madrid, Imprenta y Librería de Gaspar y Roig, editores, 1853. Tomo II, 1855 (consultado a través de NTLLE, [DVD], Madrid, Espasa, 2001).

Harris-Northall, R. (1999): "Re-Latinization of Castilian Lexis in the Early Sixteenth Century", Bulletin of Hispanic Studies, LXXVI, págs. 1-12.

Herrero Blanco, A. (1987): “¿Incluso 'incluso’? Adverbios, rematización y transición pragmática”, Estudios de Lingüística de la Universidad de Alicante, IV, págs. 177-227.

König, E. (1991): The Meaning of Focus Particles. A comparative Perspective. Londres y Nueva York, Routledge.

Kovacci, O. (1999): "El adverbio". En Bosque, I. y V. Demonte (dirs.), págs. 705-786.

Lapesa, R. (1983): Historia de la lengua española. Madrid, Gredos, 9a ed.

Lleal, C. (1995): "El secretario, el nuncio y la difusión del latinismo en el siglo XV", Lletres Asturianes, 56, págs. 19-34.

Martín Zorraquino, M. A. y J. Portolés (1999): "Los marcadores del discurso". En Bosque, I. y V. Demonte (dirs.), págs. 4051-4213.

Martínez, J. A. (1992): "Tres hipótesis sobre el origen histórico de la partícula hasta". En Actas del II Congreso Internacional de Historia de la Lengua Española. Madrid, Pabellón de España, págs. 613-630.

Moliner, M. (DUE): Diccionario de uso del español. Madrid, Gredos, 2007, $3^{\text {a }}$ ed.

Oesterreicher, W. (2004): "Textos entre la inmediatez y la distancia comunicativas. El problema de lo hablado en lo escrito en el Siglo de Oro", en R. Cano (coord.), págs. 729-769.

Pérez-Salazar, C. (2009): "Inclusivemente e inclusives: la reinterpretación de un adverbio latino". En Ars bene docendi. Homenaje al profesor Kurt Spang con motivo de su jubilación. Pamplona, Universidad de Navarra, págs. 443-455. 
Pérez-Salazar, C. (2010): "Estrategias focalizadoras en la prensa escrita. El caso de máxime e inclusive". En C. Martínez Pasamar (ed.), Estrategias argumentativas en el discurso periodístico. Frankfurt am Main, Peter Lang, págs. 171-191.

Pons Rodríguez, L. (2010): "La elaboración léxica desde modelos latinos: tres estudios de caso en el castellano medieval (inclusive, exclusive, respective)". En M. Castillo y M. López Izquierdo (eds.), Modelos Latinos en la Castilla medieval. Madrid-Frankfurt am Main, Iberoamerocana-Vervuert, págs. 81-111.

Portolés, J. (2007): "Escalas informativas aditivas. Pruebas del español". Spanish in Context, IV-2, págs. 135-157.

Real Academia Española (Diccionario usual): Diccionario de la lengua castellana compuesto por la Real Academia Española, reducido a un tomo para su más fácil uso. Quarta edición. Madrid, Viuda de Ibarra, 1803 (consultado a través de NTLLE, [DVD], Madrid, Espasa, 2001).

Real Academia Española, Corpus Diacrónico del Español (CORDE) [en línea] <HTTP:// WWW.RAE.ES> (IX-09).

Real Academia Española, Corpus de Referencia del Español Actual (CREA) [en línea] $<$ HTTP://WWW.RAE.ES> (IX-09).

Real Academia Española (NTLLE): Nuevo Tesoro Lexicográfico de la Lengua Española [DVD-ROM]. Madrid, Espasa, 2001.

Real Academia Española, Asociación de Academias de la Lengua Española (DPD): Diccionario Panhispánico de Dudas. Madrid, Santillana, 2005.

Real Academia Española (DRAE 2001): Diccionario de la Lengua Española. Madrid, Espasa, $22^{\mathrm{a}}$ ed.

Santos Río, L. (2003): Diccionario de partículas. Salamanca, Luso-Española de Ediciones.

Salvá, V. (1846), Nuevo diccionario de la lengua castellana, que comprende la última edición integra, muy rectificada y mejorada del publicado por la Academia Española, y unas veinte y seis mil voces, acepciones, frases y locuciones, entre ellas muchas americanas [...]. París, Vicente Salvá (consultado a través de NTLLE, [DVD], Madrid, Espasa, 2001).

Seco, M. (1970): Arniches y el habla de Madrid. Madrid y Barcelona, Alfaguara.

Seco, M., O. Andrés y G. Ramos (DEA): Diccionario del español actual. Madrid, Aguilar, 1999.

Stevens, J. (1706): A new Spanish and English Dictionary. Collected from the Best Spanish Authors Both Ancient and Modern [...]. To which is added a Copious English and Spanish Dictionary [...]. Londres, George Sawbridge (consultado a través de NTLLE, [DVD], Madrid, Espasa, 2001).

Verdonk, R. (2004): "Cambios en el léxico del español durante la época de los Austrias". En R. Cano (coord.), págs. 895-916. 